\title{
Museu das Remoções da Vila Autódromo: Resistência criativa à construção da cidade neoliberal.
}

Diana Bogado ${ }^{1}$

\section{Resumo}

O planejamento da cidade neoliberal que se consolida com a realização de megaeventos carrega dentre as suas implicações a redução do habitar ao habitat (Lefebvre, 2008). Levanta-se como hipótese neste trabalho que a proposta de sociedade que vem sendo modelada para residir na cidade neoliberal estrutura-se sobre o conceito do habitat. O empreendedorismo urbano (Harvey, 1996) é o fenômeno que sugere que a gestão da cidade se estabeleça nos moldes de uma gestão empresarial, alterando com isso, a condução da política urbana, que passa a submeter a reconfiguração territorial aos processos de valorização do capital de forma mais direta e acentuada. Destaca-se a dominação espacial, ferramenta necessária para adaptação do espaço à obtenção de lucro (Santos, 2011, Lefebvre 2001, Winnicott, 1975).

No contexto de preparação/realização dos megaeventos no Rio de Janeiro a prefeitura removeu aproximadamente 22.059 famílias, dentre as quais anunciava a comunidade Vila Autódromo, caso de estudo deste trabalho. A permanência da comunidade

\footnotetext{
${ }^{1}$ Diana Bogado é doutoranda em Arquitetura na Universidade de Sevilha, Espanha.
} 
culminou na construção do Museu das Remoções, fruto da luta da população frente à destruição levada a cabo pelo poder público.

A aproximação da comunidade ocorreu através da observação participante (WHYTE,1943), ou da participação observante (WACQUANT, 2000). A autora deste trabalho é atora na pesquisa-ação (TRIPP, 2005) uma vez que é pesquisadora e ativista, tendo coordenado o projeto de extensão que construiu com a comunidade o Museu das Remoções.

Palavras-chave: Museu das Remoções, Remoções, Resistência, Vila Autódromo, Olimpíadas.

\section{Abstract}

The neoliberal city model of planning that is consolidated with the mega-events brings as one of its implications the reduction of the inhabiting to the habitat (Lefebvre, 2008). The hypothesis is that the society proposed by spatial planners to the neoliberal city is structured on the concept of habitat. Urban entrepreneurialism (Harvey, 1996) is the current phenomenon suggesting that the city management is established within the parameters of business management, modifying, therefore, the conduction of urban life. The territorial reconfiguration is then submitted to the capital valorization processes in a more direct and incisive way. (Santos, 2011, Lefebvre, 2001, Winnicott, 1975). During the preparation and occurrence of the mega-events in Rio de Janeiro, the City Hall evicted approximately 22,059 families, among which it was announced the eviction of Vila Autódromo community, the case study of this research. The victory of the community had its climax in the construction of the Museu das Remoções (Museum of Evictions) created by a popular community that faced the destructing power of public authorities.

The approach of the researched community took place through a participant observation (Whyte, 1943) or, more precisely, 


\section{Diana Bogado}

an observing participation (Wacquant, 2000). The author of this work is an agent in action research (Tripp, 2005), she conducts the joint action of practice and research, and coordinator of the university project that built together the Museum of Evictions.

Keywords: Museu das Remoções, Evictions, resistance, Vila Autódromo, Olympic Games.

\section{Introdução}

Este artigo pretende descrever o Museu das Remoções e reforçar sua contextualização no campo da museologia social. Trata-se de considerações abordadas na tese de doutorado: "O Museu das Remoções da Vila Autódromo. Potência de resistência criativa e afetiva como resposta sociocultural ao Rio de Janeiro dos megaeventos"2. A narrativa deste museu, construído de forma comunitária, apresenta um outro olhar, uma outra memória das olimpíadas cujo ponto de partida é a memória da remoção da comunidade Vila Autódromo ${ }^{3}$, que enfrentou o Estado e resisitiu à remoção integral. O Museu das Remoções possui uma narrativa

\footnotetext{
2 "O Museu das Remoções da Vila Autódromo. Potência de resistência criativa e afetiva como resposta sociocultural ao Rio de Janeiro dos megaeventos" é a tese de Diana Bogado desenvolvida pela Universidade de Sevilha, Espanha. 2017. Arquiteta e urbanista com experiência em coordenação de projetos de extensão de intervenção urbanísticas em favelas no Rio de Janeiro, e desenvolvimento em conjunto de projetos participativos de arquitetura e urbanismo no Brasil e na África. Participação na idealização e criação do Museu das Remoções.

${ }^{3}$ Uma primeira versão do pensamento sobre museologia social aqui exposto foi elaborado em conjunto com Mário Chagas e lançado no livro publicado em razão do seminário "Memória das Olimpíadas: múltiplos olhares". O livro eo seminário foram organizados no âmbito do projeto "Preservação da Memória das Olimpíadas: processos e ações" pelas Fundações Casa de Rui Barbosa e Getúlio Vargas. Mario Chagas é poeta, museólogo e cientista social. Participou na idealização e criação do Museu das Remoções e é orientador da tese "O Museu das Remoções da Vila Autódromo. Potência de resistência criativa e afetiva como resposta sociocultural ao Rio de Janeiro dos megaeventos" de Diana Bogado
} 
diametralmente oposta à narrativa do Estado a respeito dos jogos olímpicos Rio 2016, ele se opõe às memórias do poder ${ }^{4}$ e se propõe a resgatar (ainda que de modo singelo) o poder da contramemória ${ }^{5}$, da memória contra-hegemônica ${ }^{6}$, da narrativa popular. Sobre este poder e sobre o conflito social decorrente dele, tratamse as seguintes linhas.

\section{O Museu das Remoções contextualizado na museologia social}

O Museu das Remoções celebra a vida e este, talvez, deva ser considerado "o" princípio da Museologia Social: Uma museologia a favor da celebração da potência da vida. Ela está interessada em reinventar os museus e compreende-los e praticálos como acontecimentos e atos que afetam e potencializam a vida, não uma vida qualquer, mas uma vida produtora de mais vida do ponto de vista relacional, social e político ${ }^{7}$. Mário Chagas $^{8}$

\footnotetext{
"Ver o texto "Memória e Poder: dois movimentos", publicado nos Cadernos de Sociomuseologia, disponível em http://revistas.ulusofona.pt/index.php/ cadernosociomuseologia/article/view/367 (última consulta 10 de dezembro de 2016).

5 Idem.

${ }^{6}$ Ver o livro O amigo \& O que é um dispositivo, de Georgio Agamben. Editora Argos. 2014. Ver também Corpo Utópico e Heterotopias. Michel Foucault. São Paulo, n-1. 2014.

7 Anotações da aula de Mário Chagas ministrada no Seminário de Museologia Social da Universidade Lusófona de Humanidades de Tecnologias, ULHT, em Lisboa, fevereiro de 2017.

8 Poeta, museólogo e cientista social. Coordenador cultural do Museu da República, professor visitante da Universidade Lusófona de Humanidades e Tecnologias e professor colaborador do Programa de Pós-graduação de Museologia da Universidade Federal da Bahia. Tem experiência no campo da museologia e da museografia, com ênfase na museologia social, nos museus sociais e comunitários, na educação museal e nas práticas sociais de memória e patrimônio. Participação na idealização e criação do Museu das Remoções, orientador da tese da arquitetua e urbanista Diana Bogado "O Museu das
} 


\section{Diana Bogado}

acrescenta que as mudanças conceituais e teóricas geradas no campo dos museus a partir desta museologia produzem transformações e aproximam a museologia de um saber-fazer "inmundo", "in-disciplinado", contaminado de vida afetiva, política e social. (CHAGAS e BOGADO, 2017)

O Museu das Remoções é uma iniciativa autônoma criada por moradores, apoiadores e amigos da Vila Autódromo?. Inaugurado no dia 18 de maio de 2016, quando se comemorava o dia internacional dos museus, ele é fruto de um processo no qual a arte, a filosofia e o conhecimento científico são colocados em favor da vida. A comunidade Vila Autódromo "enfrentou o poder destruidor do poder público e descobriu na luta o seu próprio poder" (CHAGAS e BOGADO, 2017, p. 4)

\section{O Museu das Remoções da Vila Autódromo}

A Vila Autódromo era constituída por mais de 600 famílias e situava-se na Barra da Tijuca, no Rio de Janeiro. Com o lema "Memória não se remove", a comunidade converteu-se em um museu durante as olimpíadas, que se encarregava de contar a violência do Estado praticada no processo de remoção de $97 \%$ de sua população. Entretanto, a comunidade resisitiu e permaneceu, e construiu o Museu das Remoções de forma participativa. A Rua Vila Autódromo tornou-se o museu, com exposições que trataram de contar a história das remoções a partir da perspectiva dos atingidos pela política de remoções. A museologia "com" adotada no referido

Remoções da Vila Autódromo. Potência de resistência criativa e afetiva como resposta sociocultural ao Rio de Janeiro dos megaeventos" ${ }^{8}$ em conjunto com o diretor da tese José Pérez de Lama e o orientador José María López Medina.

9 Ver https://www.brasildefato.com.br/2016/05/18/museu-das-remocoes-expoememoria-de-resistencia-da-vila-autodromo-no-rio/ 
processo já era tratada por Valdiza Russio ${ }^{10}$ que defendia as iniciativas em conjunto: uma museologia "com" a comunidade, que sugere o abandono da ideia de uma museologia "para" a comunidade. A concepção demonstra os limites da museologia normativa que dá mais valor às regras e normas do que à própria dinâmica da vida ${ }^{11}$. Em analogia as teorias trazidas por Henri Lefebvre sobre a sociedade contemporânea, a museologia tradicional insere-se nas concepções de mundo que Lefebvre (2004, p.87) considera que estão invertidas, de ponta a cabeça e propõe "re-inverter o mundo" que conforme o autor está invertido porque se centra no capital. A museologia social tem um sentido político mais profundo, reconhece o protagonismo dos indivíduos na construção e preservação da memória, com isto inverte o processo tradicional museal que preserva as memórias do poder.

Vale estender o conceito para as práticas de "pesquisa com", como as práticas de pesquisa intervenção e pesquisa-ação (TRIPP, 2005) que consistem na recusa da ideia de isenção apresentada pelas pesquisas científicas tradicionais que colocam o indivíduo como isento politicamente do campo. Em oposição à neutralidade científica, as experiências "com" sustentam que o pesquisador-ator na pesquisa-ação afeta e é afetado pelo campo. Compreensão que admite a pluralidade interna da ciência e abre-se como prática alternativa para a promoção da interdependência entre conhecimentos cientificos e não científicos. (Sousa Santos 2010, p. 36)

O Museu das Remoções nasceu da articulação autônoma comunitária (Souza, 2006; Miraftab, 2009) com apoiadores ativistas

\footnotetext{
10 Waldisa Rússio Camargo Guarnieri foi professora e museóloga, Uma das personalidades mais influentes no desenvolvimento do pensamento teórico da Museologia e de sua consolidação como campo disciplinar no Brasil. 11 Idem
} 


\section{Diana Bogado}

e contou com atuação da universidade, através de projeto de extensão à comunidade ${ }^{12}$. A experiência dotada de potência política e de potência poética ao transformar o meio, transformou cada sujeito. "O Museu das Remoções transforma todos nós" ${ }^{13}$. (Mário Chagas, 2016).

A experiência do museu articula vários atores em rede e aponta a capacidade transformadora da universidade no que se refere às questões territoriais urbanas. "A atuação das universidades junto às resistências locais (micropolítica) torna-se fundamental no contexto brasileiro para fazer frente às atuações do poder público vinculadas à macropolitica urbana"14. (RENA, 2016, p. 2, grifo meu).

O Museu das Remoções não pede permissão para ser museu; ele se assume e se afirma como museu e demonstra sua potência de criação, sua potência de resistência e sua potência de vida $^{15}$. Diante do empreendedorismo urbano (Harvey, 1996) viabilizado pelos Grandes Projetos Urbanos, GPU's, no contexto de preparação do Rio de Janeiro para os megaeventos, o museu mencionado apresenta-se como estratégia de luta pelo direito à moradia digna e pelo direito à cidade, contra a construção da

12 Projeto de extensão da Universidade de Arquitetura e Urbanismo Anhanguera, coordenado pela professora Diana Bogado.

13 Idem

14 RENA, N. (2016) Cartografías Indisciplinarias. Producción Académica Tecnopolítica del Grupo de Investigación Indisciplinar como actor en las Redes de Luchas Territoriales en Belo Horizonte. Disponível em: http://blog.indisciplinar.com/wp-content/uploads/2016/09/Artigo-Livro-MexicoTRAD-PT_ES.pdf, acessado em Dezembro 2016

15 Ver CHAGAS, Mário. MEMÓRIA E PODER: DOIS MOVIMENTOS. Cadernos de Sociomuseologia, v.19, n.19, Junho de 2009. Dsponível em: http://revistas.ulusofona.pt/index.php/cadernosociomuseologia/article/view/367. Acesso em: 15 Fev. 2017. 
cidade neoliberal excludente e autoritátia (Agamben, 2005; Mascarenhas, 2016; Harvey, 1996; Smith, 2006).

\section{Os megaeventos no Rio de Janeiro}

O contexto megaeventista prepara um terreno propicio a reordenação territorial, de forma a alterar profundamente as dinâmicas socioculturais e a organização espacial das cidades (Rolnik, 2015; Mascarenhas, 2016; Stavrides, 2016; Swyngedown, 2002, Harvey, 2016). A realização dos megaeventos, tal como ocorreu no Rio de Janeiro, desencadeia processos elististas e excludentes, apontados por Smith (1995) como "revanchistas", relacionados à retomada do poder pelas classes altas em momento de crise, quando as mesmas se sentem ameçadas. (Harvey, 2005).

O "empreendedorismo urbano" (Harvey, 2011) adotado na cidade apresenta-se como instrumento para o direcionamento da expansão e organização do território de acordo com os interesses do mercado imobiliário, determinando o planejamento a partir da sobreposição dos interesses privados aos interesses coletivos. Viabilizados por coalizões entre o mercado e a administração pública, (AGUILERA e NAREDO, 2009, p. 19) no bojo da "globalização neoliberal", os GPU's tornam-se modelo de intervenção urbana nas "cidades mundiais" (MASSEY, 2007) e são criadores de novos espaços dominados, indutores de um padrão de comportamento consumista. (Harvey, 1992; Santos, 2013)

Os espaços criados a partir dos megaprojetos não alteram somente o aspecto físico dos lugares, mas também seus aspectos social e simbólico: "as possibilidades político-econômicas da reconstrução de lugares estão coloridas pela maneira (...) da representação dos lugares" (HARVEY, 1992, p. 22). Tais intervenções são pensadas para funcionar como catalisadores de mudanças nas demais áreas da cidade a partir dos pontos 


\section{Diana Bogado}

revitalizados. O fenômeno da espetacularização, (Guy Debord, 1969), ou o empreendedorismo urbano, (Harvey, 1996) são expressões que descrevem o produto destas intervenções nos lugares (Lefevbre, 1973; Harvey, 1985; Makhlouf, 2016).

O processo de neoliberalização (Harvey, 2005) de cidades16 - atinge o Rio de Janeiro a partir da década de 1990. Na ocasião ocorria a candidatura do Rio para sediar as Olimpíadas de 2004. O plano estratégico elaborado pela prefeitura em 1993, inspirado no modelo Barcelona dos Jogos Olímpicos de 1992, reforçava as dinâmicas institucionais neoliberais na cidade. A realização de megaeventos tem potencialidade transformadora e política que coincide com os anseios neoliberais e transformou-se numa poderosa justificativa para a preparação da cidade mercadoria, como ocorreu com o Rio de Janeiro com a Copa do Mundo 2014 e com as Olimpíadas Rio 2016. Eventos que possibilitaram a realização de um planejamento urbano "mercadófilo" (Mascarenhas, 2016, p. 14).

A intervenção no território da forma como ocorre na ocasião dos megaeventos esportivos caracteriza-se pelo autoritarismo (Agamben, 2005) e pela reprodução da exclusão (Novais, 2010). A tomada de decisões ocorre sem consulta popular, a execução de projetos ocorre sem informações adequadas e completas à população (Rolnik, 2011). Estabelece-se a comunicação totalitária de via única, uma propaganda sem possibilidade de questionamento, podendo causar a "confusão dos espíritos" (Santos, 2013, p. 50). Tais procedimentos que são carcateristicos da gestão neoliberal e tornam-se ainda menos transparentes durante a realização de megaeventos que são utilizados como justificativas

${ }^{16}$ O Planejamento estratégico é um modelo de gestão que tem origem nos Estados Unidos e após ter sido implementado em Barcelona passou a ser difundido em várias cidades da América Latina, dentre elas o Rio de Janeiro. 
para a adoção de medidas emergenciais. O Estado que se estabelece nos megaeventos foge aos procedimentos normais, e converte-se em uma espécie de "Estado de exceção contínuo" (Agamben, 2005). O que leva ao entendimento que o evento é utilizado como justificativa para adoção de processos não convencionais de caráter anti-democrático. Ressalta-se que as medidas autoritárias adotadas são mais severas com as populações marginais. (Makhlouf, 2016), conforme aponta Muna Makhlouf (2016): “En Rio de Janeiro la cuestión de la seguridad está intrincadamente relacionada con ese proceso de creación y destrucción del valor de los espacios, y en él la 'pacificación' de las favelas tiene un papel preponderante. (...) en ambas ciudades (Barcelona e Rio de Janeiro) crearon mecanismos de control del espacio público." (p. 100, grifo meu).

Os megaeventos apresentam-se como potencializadores dos efeitos do megaprojetos. (Mascarenhas, 2016; Stavrides, 2016; Swyngedown, 2002; Aguilera e Naredo; 2009). As intervenções realizadas na cidade carioca foram produto de Parcerias PúblicoPrivadas como ocorreram com o Porto Maravilha e com o Parque Olímpico, responsáveis por acionar o capital público na construção de oportunidade para investidores imobiliários (Rolnik, 2015). As referidas obras realizadas para preparação da cidade para os eventos foram responsáveis pelo despejo de inúmeras favelas e ocupações, estimando-se um número de aproximadamente 70 mil

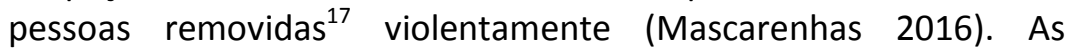

17 Em entrevista ao arquiteto Lucas Faulhaber e a jornalista Lena Azevedo "Olimpíadas servem para legitimar as remoções" Brasil de Fato, 2016. Arquiteto Lucas Faulhaber e a jornalista Lena Azevedo. Disponivel em http://www.brasil247.com/pt/247/favela247/180406/\%E2\%80\%9COlimp\%C3\%AD adas-servem-para-legitimar-as-remo\%C3\%A7\%C3\%B5es\%E2\%80\%9D.htm, acessado em Abril, 2017. 


\section{Diana Bogado}

consequências são "acumulação por despossessão", acentuação da desigualdade territorial e da marginalidade. (Harvey, 1996).

Ressalta-se que as favelas abrigam $22 \%$ da população do Rio de Janeiro o que corresponde 1.702 .073 habitantes ${ }^{18}$. As ações Estatais historicamente na cidade foram responsáveis tanto pelo aparecimento das favelas, quanto pela sua reprodução (ABREU, 2008), acentuando o problema através da política de remoções. A construção do Parque Olímpico para olimpíadas de 2016, por exemplo, apresentou-se como grande negócio para os donos de construtoras, além de ter sido justificativa para a remoção de favelas no bairro e adjacências. A supressão de comunidades inteiras como ocorreu na ocasião dos megaeventos na cidade destrói esferas simbólicas e sociais e apaga as histórias locais dos lugares atingidos. (GARNIER, 2014).

Com a intenção de denunciar o violento processo sofrido pela Vila Autódromo, na tentativa de remoção levada a cabo pela Prefeitura Municipal do Rio de Janeiro, a comunidade construiu o Museu das Remoções. Fruto da luta criativa e resiliente que tratou de reconstruir (ainda que em parte) a relação entre o território e a memória local após a remoção de $97 \%$ da comunidade. O Museu das Remoções contrapõe-se à dinâmica de esquecimento e apagamento praticada pelas remoções.

\section{A Construção do Museu das Remoções}

A construção do museu ocorreu em três etapas, a primeira consistiu na idealização do museu dentro da concepção de museu comunitário, a segunda contou com a realização de diversas oficinas de resgate da memória popular e a terceira consisitiu na intervenção territorial no espaço público da Vila Autódromo, que

${ }^{18}$ Dados do Instituto Brasileiro de Geografia e Estatística, IBGE, de 2010. 
resultou na construção de sete esculturas construídas nos lotes que tiveram suas edificações demolidas pela prefeitura: "Vila de Todos os Santos", em homenagem à casa da Dona Heloísa Helena Berto; "Penha de muitas faces", escultura em homenagem à casa da Dona Maria da Penha Macena; "Suporte dos males" em homenagem à casa de Dona Jane Nascimento; "Luz que não se apaga", única escultura que se relaciona a uma edificação que não foi removida a Igreja São José Operário. Decidiu-se homenagear a igreja pelo simbolismo que esta edificação tem para a comunidade, tendo acolhido muitos moradores que tiveram suas casas demolidas; "Doce infância", escultura em homenagem ao Parquinho; "Espaço Ocupa e Casa da Dona Conceição", escultura que faz referência aos Festivais Ocupa Vila Autódromo a casa da Dona Conceição Queiroz; "A Associação sou eu" uma homenagem à Associação dos Moradores da Vila Autódromo ${ }^{19}$. As esculturas foram construídas no âmbito do projeto de extensão universitária e constituem-se de escombros da própria comunidade. Elas buscam trazer à tona a memória social local e denunciar o violento processo de remoção das casas $^{20}$.

No contexto descrito, assinala-se a progressiva perda de direitos, e os movimentos sociais se organizam com estratégias correspondentes aos "mecanismos biopolíticos" do poder público. (Zibechi, 2011, p. 16). A articulação dos que vivem excluídos dos processos hegemônicos faz emergir um cotidiano particular ao espaço marginal carioca (com as características de um país precarizado e emergente), "um novo cenário geopolítico decisivo" (Davis, 2007), caracterizado pela predominância do aspecto do vivido diante das demais categorias Lefebvrianas de compreensão

\footnotetext{
${ }^{19}$ Ver https://www.facebook.com/museudasremocoes/?fref=ts

20 Prefeitura removera 119 favelas ate fim de 2012. Disponível em http://oglobo.globo.com/rio/prefeitura-removera-119-favelas-ate-fim-de-20123072053, acessado em Agosto de2016.
} 


\section{Diana Bogado}

espacial (Lefebvre, 2011). A forma de produção socioespacial das periferias, em função da dinâmica cotidiana destes lugares," 'fora de controle dos poderosos" (Zibechi, 2011, p. 20), é marcada pela prática do habitar, forma de ser, estar e viver que faz alusão à vida, à multiplicidade e à amplitude da existência e das possibilidades. $\mathrm{O}$ habitar abrange a complexidade do ser humano nas dimensões do desejo, do corpo e da sua multifuncionalidade e da subjetividade em contraposição ao habitat que reduz o ser humano às funções metabólicas de comer, dormir e reproduzir-se e é o dado de referência para a elaboração dos projetos arquitetônicos e urbanísticos da atualidade. $\mathrm{O}$ ato de habitar é revolucionário porque é capaz de opor-se dialeticamente ao processo de homogeneização do capital (Lefebvre, 2001).

A produção socioespacial das periferias caracterizada pela luta cotidiana pela sobrevivência definida como "urbanismo insurgente" por Miraftab (2009) ou como "sociologia das emergências" por Sousa Santos (2004) dá a tônica dos movimentos sociais contemporâneos, cujo conflito emerge como resposta ao urbanismo neoliberal. Fruto da atuação autônoma dos sujeitos sociais (Souza, 2006) tal conflito gera propostas participativas de construção da cidade. Práticas que são chamadas de diversas formas: urbanismo insurgente (Miraftab, 2009); urbanismo de guerrilla $^{21}$ (Pagano, 2014); movimentos de re-territorialização ${ }^{22}$ (Matarán, 2013); cosmopolitismo subalterno (Sousa Santos, 2010); irracionalidades (Santos, 2013); transborde social, como derivação

\footnotetext{
${ }^{21}$ PAGANO, Celeste. DIY URBANISM: PROPERTY AND PROCESS IN GRASSROOTS CITY BUILDING Forthcoming in the Marquette Law Review, 2014. Disponível em https://ciudadinsurgente.files.wordpress.com/2014/05/diy-urbanism-propertyand-process-in-grassroots-city-building-c-pagano.pdf, acessado em Abril de 2017.

${ }^{22}$ Ver MATARÁN, A. Participación social en la protección activa de los espacios agrarios periurbanos: un estado de la cuestión. Boletín de la Asociación de Geógrafos Españoles, 2013.
} 
do conceito de transborde urbano, cujo reconhecimento do conflito sugere o direito ao transborde, entendido como translação da terminologia do direito à cidade (schelotto, 2013); entre outras definições. A forma de vida mencionada carrega a prática da construção da cidade pelos próprios habitantes, considerada contra-hegemonica por desestabilizar a ordem normalizada. (Miraftab, 2009). Neste sentido "as periferias urbanas representam uma das fraturas mais importantes em um sistema que tende ao caos $^{\prime \prime 23}$. (ZIBECHI, 2011, p. 18)

As lutas pela sobrevivência ou resistência aos processos de exclusão, em inúmeros casos, para além da capacidade de resiliência, possuem caráter revolucionário (Miraftab, 2004, 2009). Muitas vezes tais experiências conquistam direitos à população e conseguem inviabilizar projetos municipais excludentes. Como é o caso da Vila Autódromo, luta insurgente articulada em rede contra a exclusão econômica, social e política gerada pela globalização neoliberal (Sousa Santos, 2006).

A tese: "O Museu das Remoções da Vila Autódromo. Potência de resistência criativa e afetiva como resposta sociocultural ao Rio de Janeiro dos megaeventos"

Tendo como objeto de estudo a referida luta, contextualizada na preparação da cidade para as Olimpíadas 2016, a tese "O Museu das Remoções da Vila Autódromo. Potência de resistência criativa e afetiva como resposta sociocultural ao Rio de Janeiro dos megaeventos" pretende problematizar as devidas implicações socioespaciais e simbólicas das articulações marginais

\footnotetext{
${ }^{23}$ Tradução da autora.
} 


\section{Diana Bogado}

contra o modelo hegemônico para a cidade, para a política e para os cidadãos.

No caso da Vila Autódromo a história da comunidade e os elementos materiais e imateriais inerentes a ela foram suprimidos com a remoção de $97 \%$ da comunidade, que também engendra a destruição em outros âmbitos (Garnier, 2014) como do patrimônio cultural, dos modos vida, da produção socioespacial, do habitar, entre outros. Lefebvre (2001) acrescenta que o ser humano só pode habitar como poeta, e se lhe é negado a possibilidade de habitar poeticamente ele inventará à sua maneira. O cotidiano mais irrisório para o autor possui resquícios de espontaneidade poética, exceto quando imerso no mundo da mercadoria tendo o uso do cotidiano substituído pelo valor de troca.

A construção do Museu das Remoções apresenta-se como resposta de luta trangressiva e insurgente que contrapõe-se à proposta do Estado e à produção hegemônica do habitat urbano resistindo com poesia, afetividade e resiliência às imposições hegemônicas (Massey, 2009; Souza, 2006; Mirafitab, 2009; Lafebvre, 2001; Zibechi, 2011; Scott, 1990). O conceito de insurgência propõe a descolonização das teorias de planejamento ao incorporar a contra-hegemonia, a transgressividade e a imaginação, (Miraftab 2004, 2009); enquanto a resiliência constata a capacidade de adaptação e reorganização após mudanças conservando essencialmente a mesma função, estrutura e identidade (WALKER, 2004) ${ }^{24}$.

O espaço da referida comunidade institui uma luta discursiva de disputa de significados no campo cultural ao poder estabelecido que dá lugar à criação de identidades baseadas na dignidade e na

24 WALKER, B. (2004) resilience, adaptability and transformability in socialecological system Ecology and society, 9 (2), p. 5 
autonomia. (Scott, 1990). A identidade não está ancorada em um lugar físico, mas nos afetos, no vivido em comum (Zibechi, 2006, p.52). ${ }^{25}$ Contextualizado numa proposta de resgate de memória que foge do circuito dos museus tradicionais - nos quais o espaço, a memória e os objetos são utilizados para recortar a memória da comunidade e compor museus ${ }^{26}$ - este museu nasce da práxis, baseado em uma museologia "comprometida com a cidadania, com a humanidade e com a afetividade". (Chagas, 2017) ${ }^{27}$. A memória que o Museu das Remoções se propõe a resgatar "é mais interessante que as grandes vinculações de memória porque a memória fundamenta tudo, mas o mais importante é o presente" ${ }^{28}$. Para Moutinho a museologia aqui mencionada é apelidada "museologia do afeto" ${ }^{29}$ porque é de outro mundo uma vez que não tem nada a ver com este mundo que é o mundo do neoliberalismo. As considerações de Moutinho dialogam com as concepções do mundo invertido e de valor de uso do cotidiano mencionadas (Lefevbre, 2001).

\footnotetext{
${ }^{25}$ Dibujando fuera de los márgenes ¿Movimientos sociales o sociedad en movimiento?

En América Latina. Entrevista de Susana Nuin a Raúl Zibechi, 2006.

$26 \mathrm{Na} 23^{\circ}$ Conferência Geral do Conselho de Museologia MINOM, "Museologia do Afeto", disponível em https://www.youtube.com/watch?v=6PZIOTMOKtM, acessado em Fevereiro de 2017

27 Anotações da aula de Mário Chagas ministrada no Seminário de Museologia Social da Universidade Lusófona de Humanidades de Tecnologias, ULHT, em Lisboa, fevereiro de 2017.

${ }^{28}$ Palavras de Mário Moutinho. Diretor da $23^{\circ}$ Conferência Geral do Conselho de Museologia MINOM 2013, no Rio de Janeiro, "Museologia do Afeto", disponível em https://www.youtube.com/watch?v=6PZIOTMOKtM, acessado em Fevereiro de 2017MINOM 2013 do Rio de Janeiro

$2923^{\circ}$ Conferência Geral do Conselho de Museologia MINOM, "Museologia do Afeto", disponível em https://www.youtube.com/watch?v=6PZIOTMOKtM, acessado em Fevereiro de 2017
} 


\section{Diana Bogado}

A tese sobre o Museu das Remoções descreve a construção deste museu como potência de luta social frente às transformações urbanas levadas a cabo no Rio de Janeiro no contexto olímpico, que culminaram na reorganização territorial propícia à reprodução do capital. Dentre os objetivos o trabalho pretende;

Observar as consequências para a cidade desta nova forma de gestão urbana caracterizada pelo casamento do Estado e do capital. (Borja e Forn, 1996; Aguilera e Naredo, 2009)

Registrar as consequências da referida forma de gestão urbana para a população, principalmente no que se refere à questão habitacional, com ênfase no impacto à população moradora de favelas e periferias. (Makhlouf, 2016).

Analisar a experiência do Museu das Remoções da Vila Autódromo como resistência criativa e afetiva à consolidação do Rio de Janeiro neoliberal

A partir do estudo de caso da comunidade Vila Autódromo, a tese ressalta a permanência de 20 famílias na Vila Autódromo diante de 77 mil famílias removidas ${ }^{30}$ para as Olimpíadas Rio $2016^{31}$. A Vila Autódromo foi a única favela que resistiu a chamada 'remoções olímpicas' em um cenário de maior execução de remoções de favelas na historia $^{32}$. Indaga-se a razão da

${ }^{30}$ Resistir é preciso: 77 mil pessoas removidas no Rio em sete anos. A Voz da Favela, Agosto de 2016.

${ }^{31}$ Desde 2009 quando o Rio de Janeiro foi anunciado como cidade-sede dos jogos. Dados no Dossiê do Comitê Popular Copa e Olimpíadas 2016. Disponível em https://medium.com/@jogosdaexclusao/o-rio-de-janeiro-dos-jogos-daexclus\%C3\%A3o-104624e70\#.o2lwjirft, acessado em Fevereiro de 2017.

32 Dados no Dossiê do Comitê Popular Copa e Olimpíadas 2016. Disponível em https://medium.com/@jogosdaexclusao/o-rio-de-janeiro-dos-jogos-daexclus\%C3\%A3o-104624e70\#.o2lwjirft, acessado em Fevereiro de 2017. 
permanência desta comunidade contra as pretensões de remoção da mesma anunciada pelo Estado.

A partir da base teórica, fundamenta na interdependência entre conhecimentos cientificos e não científicos ${ }^{33}$ (Souza Santos, 2010 p. 36) e da aplicação da ferramenta da pesquisa-ação ${ }^{34}$ (Tripp, 2005; Malo, 2004) esta tese considera como hipótese, que a rede de solidariedade e afeto presente na vida comunitária das favelas reprodutora do habitar, no âmbito do vivido, - estruturada sob a construção de vínculos sociais mais sólidos que os estabelecidos nos espaços urbanos concebidos (habitat) - (Lefebvre, 2001) é capaz de criar bases de resistência afetivas que dificultam desintegração socioespacial levada a cabo com a construção da cidade neoliberal.

A aproximação da comunidade estudada ocorre através da observação participante (WHYTE,1943), ou, mais precisamente, da participação observante (WACQUANT, 2000; MALO, 2004). A ferramenta metodológica adotada deve-se à autora desta tese realizar simultaneamente pesquisa e ativismo no movimento social de resistência à remoção da comunidade ${ }^{35}$. Esta articulação do posicionamento de militante e pesquisadora é interessante à pesquisa no que trata do debate da subjetividade e objetividade, e também a respeito da ilusão da neutralidade científica. A

\footnotetext{
${ }^{33}$ A "ecologia dos saberes" é o pensamento pósabismal que pressupõe a ideia de uma diversidade epistemológica do mundo e o reconhecimento da existência da pluralidade de conhecimento além do conhecimento científico. (Boaventura de Sousa Santos, 2010, p. 33)

${ }^{34}$ Ver MALO, M. "Nociones comunes Nociones comunes. Experiencias y ensayos entre investigación y militancia". Revista Derive Approdi, precariasa la deriva, Revista Posse, Colectivo situaciones, Grupo 116, Colectivo Sin Ticket. Traficante de sueños, Madrid, 2004

${ }^{35}$ A autora deste trabalho, inserida na luta comunitária, participou do processo de construção do Museu das Remoções.
} 


\section{Diana Bogado}

perspectiva metodológica adotada é a pesquisa-participativa desenvolvida a partir da confluência de várias correntes da pesquisa-ação. Dentro desta perspectiva considera-se a práxis como eixo dos processos de transformação social em ciclos de ação-reflexão-ação (Virno, 2003, Malo, 2004, Montañés, 2009).

Pressupõe-se, também como hipótese, que os processos desencadeados pela ação hegemônica na preparação do Rio de Janeiro neoliberal geram novas demandas de luta dos movimentos sociais (Harvey, 1996; Miraftab, 2009; Santos, 2013), principalmente de favelas; por estas serem diretamente atingidas com a gestão empreededora da cidade. Considera-se que os movimentos sociais das periferias, em função das inúmeras violações sofridas, passam a se rearticular de forma criativa e inovadora a fim de respondê-las, marcando a insurgência de um novo contexto de resistência social mais elaborada, diversificada e organizada em rede, entendida como uma nova forma de resistência (Castells e Borja, 1996; Harvey, 2016) que equivale aos mecanismos biopolíticos usados pelo Estado (Zibechi, 2011).

Também considera-se como hipótese que a conquista da permanência da comunidade se deve aos modos de vida locais, próprio do habitar das favelas do Rio de Janeiro, que contem a substância da espontaneidade e da afetividade fortalecedora dos vínculos (Lefebvre, 2001; Zibechi, 2006). A produção socioespacial da comunidade foi elemento fundamental à continuidade da luta, o cotidiano possibilitou o comprometimento e a confiança entre os sujeitos, sustentado pela dignidade (Scott 1990), - qualidade relacionada à conciência do próprio valor e ao autoreconhecimento de si mesmo como sujeito social e político ativo (Sousa, 2006) - que nutre os sentimentos de consideração e de coletividade.

A articulação em rede tecida no bojo dos novos movimentos sociais é peça chave desta vitória. As redes que tem como base a 
solidariedade e a reciprocidade desenham uma realidade na qual a confiança é a base das relações sociais. Esta rede de reciprocidade constitui a comunidade marginal urbana. (LOMNITZ, 1975, p. 223).

O modelo autônomo de produção socioespacial das periferias (Zibechi, 2011) dotado de possibilidade de construção de vínculos afetivos contribuiu decisivamente para persistência da luta criativa no âmbito do movimento social. A luta pelo direito à moradia seria, portanto, mais potente nas periferias que possuem redes de solidariedade mais fortes, como no caso da Vila Autódromo.

$E$, finalmente, a partir das hipóteses mencionadas, entendese a luta da Vila Autódromo dotada de potencia transformadora; devido tanto aos modos locais de reprodução socioespacial quanto à copresença radical (Sousa Santos, 2010, p. 32), cuja resistência dá condição para realização do urbanismo de conflito, aquele que não atende à dominação neoliberal (Miraftab, 2009).

Observa-se no microespaço da comunidade Vila Autódromo o caso de produção socioespacial autônoma e criativa do Museu das Remoções, que responde ao urbanismo neoliberal com dinâmicas socioespaciais radicais, articuladas em rede de solidariedade e reciprocidade (LOMNITZ, 1975) que opõem-se dialeticamente aos processos de homogeneização do capital (Lefebvre, 2004). Dentre as quais se destacam os processos de apropriação do espaço público, de participação cidadã e da permanência da comunidade no local. A síntese metodológica pode ser observada no seguinte esquema: 
Diana Bogado

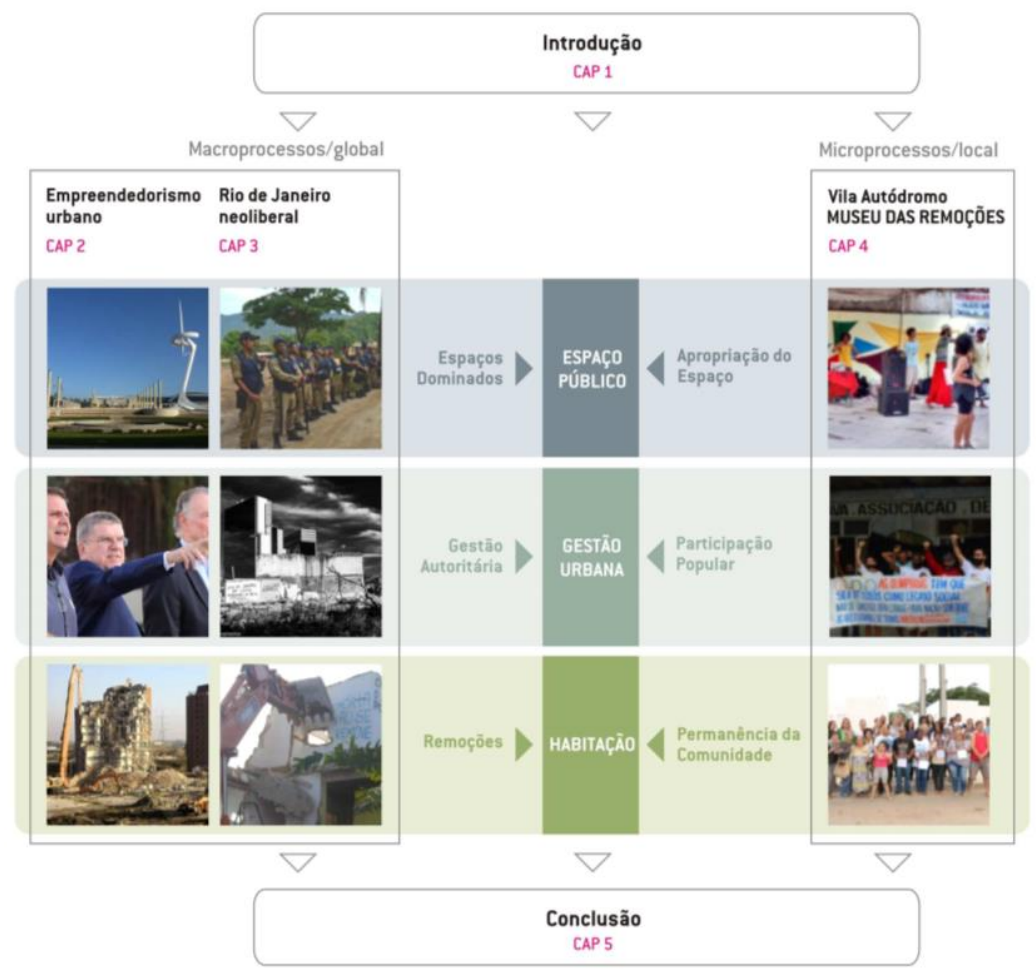

Fig. 1. Esquema metodológico da pesquisa. Elaboração própria.

\section{Considerações finais}

Para concluir reforça-se que Museu das Remoções contextualiza-se na experiência de luta e disputa da cidade ao contrariar os espaços dominados e privatizados com apropriações, ao contrariar a gestão urbana autoritária com participação popular e autoconstrução, ao contrariar a produção da segregação espacial 
com permanência e ao contrariar a proposta de uma cidade de consumo e de aparências baseada no valor de troca com um cotidiano solidário que priorisa o valor do uso e (Lomnitz, 1975) reterritorializa (Matarán, 2013). A Vila venceu porque a rede comunitária, tecida de vínculos e afetos - baseados em dignidade e em autonomia (Scott 1990) - construída no âmbito do habitar (Lefebvre, 2001), levou os indivíduos, a optarem renunciar às ferramentas biopolíticas (Zibechi, 2011) manipuladas pelo poder. E, desta forma, ao afirmar que "Nem todos tem um preço" ${ }^{36}$ transcendeu aos campos de atuação deste poder. Ao manterem-se com este propósito, os sujeitos autônomos (Souza, 2006) da comunidade afetaram as pretensões da organização territorial neoliberal (macroprocesso) com a construção do Museu das Remoções (microprocesso) como um "contrapoder popular que vem debaixo" (Zibechi, 2011) com potência transformadora. O museu comunitário em questão, afirmou por entre as rachaduras do projeto hegemônico da cidade olímpica, que a memória da Vila Autódromo é viva e "não se remove" ${ }^{37}$.

\section{Referências bibliográficas}

AGAMBEN, G. Homo Sacer. Sovereign Power and Bare Life. Stanford: University press, 2005.

AGUILERA, F. y NAREDO, J. Interés y contexto del tema tratado. Economía, poder y megaproyectos. Madrid: Cromoimagen S.L., 2009 (p. 13 - 18)

BORJA, Jordi; FORN, Manuel. Politicas da Europa e dos Estados para as Cidades, Espaço e Debates, São Paulo, n. 39, p. 32-47, 1996

\footnotetext{
${ }^{36}$ Afirmação dos moradores da Vila Autódromo, declarada oralmente e escrita nas paredes das casas que foram removidas.

37 "Memória não se remove". Frase que se tornou o slogam do Museu das Remoções.
} 


\section{Diana Bogado}

CASTELLS, Manuel \& e BORJA, Jordi. "As cidades como atores políticos", em Revista Novos Estudos CEBRAP, N 45, julho/ 1996, SP, p 152/166

CHAGAS, M. e BOGADO, D. Memória das Olimpíadas: múltiplos olhares, organizados no âmbito do projeto Preservação da Memória das Olimpíadas: processos e ações. Casa de Rui Barbosa, Rio de Janeiro, 2017.

GARNIER, J.P. Marsella 2013: el urbanismo como arma de destrucción masiva. GeocritiQ. 10 de enero de 2014, nº 24.

HARVEY, David The urbanization of capital. Oxford: Basil Blackwell, 1985

"From Space to Place and Back Again: Reflections on The Condition of Postmodernity", in BIRD, J et al. (Eds.), Mapping the Futures. Local Cultures, Global Change, Routledge, Londres, 1992.

"Do gerenciamento ao empresariamento: a transformação da administração urbana no capitalismo tardio". In: Espaço \& Debate. São Paulo: Núcleo de Estudos Regionais e Urbanos, $n^{\circ} 36,1996$

Annablume, 2005.

A produção capitalista do espaço. São Paulo: .A condição pós-moderna. São Paulo: Loyola, 2011

LOMNITZ, Larissa. Como sobreviven los marginados, 1975.

LEFEBVRE, Henri, Espaço e Política, 1973. . The production of space. Oxford: Blackwell, 1991.

Moraes, 2001. . O direito à cidade. São Paulo: Ed. Centauro,

Horizonte:EDUFMG, 2004.

A Revolução Urbana. Belo MASCARENHAS, Gilmar 2016, p.52. Revista USP, São Paulo, n. 108, p. 49-56. Jan. a mar. 2016

MAKHLOUF, Muna. "Conexiones entre la Barcelona postolímpica y el Rio preolímpico a través de la resistencia a planes urbanisticos". In: CUNHA, N.; FREIRE, L; MACHADIMARTINS, M; VEIGA, F. (org.) Antropologia do conflito urbano: 
Museu das Remoções da Vila Autódromo

Conexões Rio-Barcelona. Rio de Janeiro Lamparina, Le metro, CNPq. 2016.

MORIN, Edgar. "El Método. La naturaleza de la naturaleza". Madrid: Cátedra, 1986.

MIRAFTAB, Faranak. Insurgent planning: situating radical planning in the global south. Planning Theory, 2009

ROLNIK, Raquel. A Guerra dos Lugares: A colonização da terra e da moradia na era das finanças. Ed. Boitempo, 2015.

áreas centrais, 2011.

. O Porto Maravilha e a política de reabilitação de

SANTOS, Milton. Por uma outra globalização: Do pensamento único à consciência universal. Rio de Janeiro: Record, 2013

SCHELOTTO, S. (Des)Bordes Urbanos. Política, proyecto y gestión sostenible en la ciudad de la periferia. En VV.AA., [Des]Bordes Urbanos (VP Monografías, n. ${ }^{\circ}$ 01). Montevideo: Unidad Permanente de Vivienda, Facultad de Arquitectura, UdelaR, 2013

SCOTT, James C. Domination and the Arts of Resistance. Yale University, 1990.

SMITH, N. A gentrificação generalizada: de uma anomalia local à regeneração urbana como estratégia urbana global. Tradução BARRETO, H. In: BIDOU-ZACHARIASEN, Catherine, De volta à cidade. São Paulo: Ed. Annablume, 2006

SOUZA, M. Mudar a cidade: uma introdução crítica ao planejamento e a gestão urbanos. Rio de Janeiro: $4^{\mathrm{a}}$ ed. Bertrand Brasil, 2006

SOUSA SANTOS, Boaventura. "Para descolonizar Occidente. Más Allá Del pensamiento abismal", 2010

STAVRIDES, Stavros. Olimpíadas de Atenas 2004: Um estado de exceção urbano que se transformou em regra. In: Os megaeventos e a cidade: perspectivas críticas, Rio de Janeiro: Letra Capital, 2016.

SWYNGEDOUW, E. "Neither Global nor Local "Glocalization" and the Politics of Scale". In: Spaces of Globalization: reasserting the power of the local. Edited by Kevin R. Cox. New York: The Guilford Press, 1997. 


\section{Diana Bogado}

TRIPP, David. "Pesquisa-ação: uma introdução metodológica". In: Educação e Pesquisa, São Paulo, v. 31, n. 3, 2005. p. 443-466. VIRNO, Paolo "Virtuosismo y revolución. Notas sobre el concepto de acción política", em "Virtuosismo y revolución. La acción política en la era del desencanto," Traficantes de sueños, Madrid, 2003, p. 89-116.

WALKER, B. et al. (2004) resilience, adaptability and transformability in social-ecological system Ecology and society, 9 (2), p. 5

WACQUANT, Loïc. Corpo e Alma. Notas Etnográficas de um Aprendiz de Boxe. Rio de Janeiro: Relume Dumará, [2000] 2002. $294 \mathrm{p}$.

WINNICOTT, D. Jeu et Réalité. L'espace potential, Paris, Gallimard, 1975.

WHYTE, Willian Foote. Sociedade de esquina. Rio de Janeiro: Jorge Zahar Ed., [1943] 2005.

ZIBECHI, R. Territorios em resistência. Cartografía política de lãs periferias urbanas latinoamericanas. Málaga, 2011 